\title{
Validity Evidence of a Brazilian Version of the Moral Foundations Questionnaire
}

\author{
Luana Vianez Moreira* (D), Mariane Lima de Souza, \& Valeschka Martins Guerra \\ Universidade Federal do Espirito Santo, Vitória, ES, Brasil
}

\begin{abstract}
Morality is a human phenomenon that involves sensitivity and skills developed by the individual throughout their social life. Considering the importance of measuring the moral concerns of adults, this paper sought validity evidence for a Brazilian version of the Moral Foundations Questionnaire. Two studies were conducted, using exploratory and confirmatory factor analysis. In the first study, 341 adults (63\% women) responded to the on-line questionnaire translated and adapted to Brazilian Portuguese. The results indicated a two-factor structure, and reduced items. In the second study, 371 adults (61\% women) participated. Results confirmed the two-factor structure (binding morality and individualizing morality). We conclude that the QFM has satisfactory psychometric properties for use in research.
\end{abstract}

KEYWORDS: psychological assessment, validity evidence, social cognition, moral.

\section{Evidências de Validade de uma Versão Brasileira do Questionário de Fundamentos Morais}

\begin{abstract}
RESUMO - A moral é um fenômeno humano que envolve sensibilidade e habilidades desenvolvidas pelo indivíduo ao longo de sua vida social. Considerando-se a relevância de mensurar as preocupações morais de indivíduos adultos, buscou-se evidência de validade para uma versão brasileira do Questionário de Fundamentos Morais. Foram realizados dois estudos com uso de análises fatoriais exploratória e confirmatória. No primeiro estudo, 341 adultos ( $63 \%$ mulheres) responderam ao Questionário virtual, traduzido e adaptado para o português brasileiro. Os resultados indicaram uma estrutura bifatorial, e uma redução dos itens. Do segundo estudo participaram 371 adultos (61\% mulheres). Os resultados confirmaram a estrutura bifatorial (moral vinculativa e moral individualizante). Conclui-se que o QFM apresenta características psicométricas satisfatórias para uso em pesquisa.
\end{abstract}

PALAVRAS-CHAVE: avaliação psicológica, evidências de validade, cognição social, moral

Moral psychology is a growing field of study that seeks to understand how human beings function in moral contexts. Currently, the main theoretical approaches follow two main lines of thought: the traditional one, which began associated with developmental psychology, based on Jean Piaget's studies on moral concepts and reasoning, and the sociocultural line, which was the result of a synthesis of research on social, evolutionary and neurological psychology, which sees emotions and moral intuitions as central phenomena (Haidt, 2014). The latter has been focused on understanding the morality foundations and searching for its origins considering the complexity and

*E-mail: luanavianez@hotmail.com

- Submetido: 14/10/2016; Revisado: 10/08/2017; Aceito: 12/04/2018. 
high human brain sophistication, which builds its moral knowledge within an equally complex sociocultural context.

In this perspective, Haidt (2007) and Haidt and Joseph (2008) proposed that the moral functioning foundations come from sensitivity and perceptual-social skills developed by the individual, based on the understanding that mind and culture develop mutually. Morality is then seen as this intuitive base of sensitivities and skills elaborated through culture, and it can be expanded and refined throughout social life. Based on this conception, Graham et al. (2011) presented a theoretical model, called Moral Foundations Theory (MFT), which measures people's moral concerns by the degree of agreement or disagreement regarding a set of moral intuitions. It is an alternative approach to the traditional dichotomy between cognitive and affective aspects of moral judgment by also inserting the cultural dimension as an important modulator of intuitive evaluations (Haidt \& Graham, 2007). Rather than a simple rule learning (moral content), morality comes to be understood from its function, in which the institutions and technologies of each population, formed from historical and cultural specificities, restrict and enable the ways in which persons interact with each other (Graham et al., 2011).

In this sense, moral systems are perceived as a social cognition that emerges from the interaction of many people. "Moral systems are interlocking sets of values, virtues, norms, practices, identities, institutions, technologies, and evolved psychological mechanisms that work together to suppress or regulate selfishness and make cooperative social life possible." (Haidt \& Kessebir, 2010, p. 800).

Thus, it is possible to state that MFT is based on a socio-intuitionist perspective of morality that understands moral concerns and judgments as modulated intuitions defined by the social and cultural context. That is, for the social-intuitionist approach (Haidt, 2001), moral judgment results from rapid and automatic evaluations that may (or may not) be followed by reason. Consequently, although its importance is not disregarded by this approach, moral reasoning is reallocated as an aspect to be considered posteriorly to moral judgment.

The morality intuitive component is defined, in turn, as this judgment that suddenly appears in consciousness, permeated by an affective valence (like or dislike, good or bad) without the need to find or think about the evidence to come to a conclusion (Haidt, 2001). Above all, it is an instantaneous feeling of approval or disapproval in the face of a situation with moral content, possibly built within each population's culture. Although intuitive responses suddenly appear in consciousness when evaluating a situation with moral content, according to the approach, that does not mean that people are hostage to this type of answer. There are indications that it can be nullified by using conscious reasoning (analyzing costs versus benefits of a given situation); by reframing the situation from a new angle or its consequences; or by talking to someone who brings new arguments that trigger new intuitions (as a result of social interaction) (Haidt, 2001).

Surveys conducted on scientific databases show that the empirical study of moral judgment performed from the social-intuitionist perspective has gained prominence in recent decades (Cushman, Young \& Hauser, 2006; Graham, Nosek \& Haidt, 2012; Haidt, Koller \& Dias, 1993; Jansson \& Dorrepaal, 2015; Moll, Oliveira-Souza \& Zahn, 2008; Shweder, Much, Mahapatra \& Park, 2003; Wheatley \& Haidt, 2005; Yilmaz, Harma, Bahçekapili \& Cesur, 2016). This perspective gives greater visibility to the role of culture in structuring the psychological mechanisms involved in moral judgment, as well as providing new insights for understanding this human phenomenon.

Even studies that are not based on MFT have presented evidence that seems to corroborate the moral intuitionist assumption. Research on moral sensitivity suggests that in the face of moral conflict, cognitive schemes or previous tacit knowledge are triggered automatically, and these processes happen below the level of conscious thought (Rest, Narvaez, Bebeau \& Thoma, 1999). Through an extensive examination on the scientific literature another study on the neural basis of moral cognition (Moll, Oliveira-Souza \& Zahn, 2008), raised a hypothesis very similar to MFT. These authors suggested that moral motivations are formed by an association of feelings and moral values that are based on moral knowledge, which is the result of abstract social knowledge associated with skills in interpersonal and cultural contexts.

Although the research on the processes that underlie human morals follow different theoretical paths, the proposal finds support in studies of related areas. Thus, it seems promising to understand moral judgment as an intuitive process and moral issues as universal, present in all cultures, varying only with regard to their scale of importance in each culture (Boer \& Fischer, 2013; Graham, Meindl, Beall, Johnson \& Zang, 2016; Hofmann, Wineski, Brandt \& Skitka, 2014; Weber \& Frederico, 2013). 


\section{MORAL FOUNDATIONS QUESTIONNAIRE}

One of the main MFT inspirations was the cultural investigation into morality and origins of human suffering launched by Shweder, Much, Mahapatra, and Park (2003). In this study, three major sets of moral values were verified, associated with the ethics of individual autonomy (freedom of choice, equity), the ethics of community (duties, hierarchy, interdependence, loyalty, sacrifice), and the ethics of divinity (purity, sanctity, cleanliness, sacred order), which together described the ethical experiences of India's people. Other studies of Western culture have also pointed out that human morality involves concerns that go beyond individual concerns about harm and fairness (Douglas, 1966; Rozin, Haidt \& McCauley, 2000).

In summary, these findings have suggested that the main building blocks of human morality relate to how individuals treat each other, including how individuals position themselves as members of a group, in order to make life in society possible. Based on this understanding, Graham and colleagues began a search for common moral values from different cultures through a transdisciplinary review of the scientific literature. This review resulted in the selection and testing of key foundations that underlie how cultures narrate their moral concerns, namely, harm and fairness (corresponding to the ethics of autonomy), authority and in-group (related to the ethics of community), and purity (corresponding to the ethics of divinity). Such results seem to be consistent with other taxonomic proposals of moral psychology, including the works of Fiske (1992), and Shweder et al. (2003).

Recognizing the wide variety of moral systems constituted in each society, the MFT started defining the main moral concerns in order to develop a questionnaire (Haidt \& Joseph, 2008; Graham et al., 2011). Harm was then defined as those human concerns regarding emotional sensitivity related to detecting and caring for people who suffer, and protecting vulnerable ones (e.g., "avoiding harm to others"). Concerns about fairness referred to feelings that motivate altruism and social reciprocity beyond family relationships, for their potential to generate gains for the social organism and consequently for the individual (e.g., "morality is doing the right thing to ensure fair treatment for all"). In-group has been based on the human tendency to organize into groups according to blood kinship, trivial similarities, religions, etc. (e.g., "morality is having a system that protects social institutions such as family, community and country"). Concerns about authority have been associated with hierarchical organization, including emotions and behaviors related to authority and power, as well as respect for traditions (e.g., "matters of duty, regardless of personal desires and purposes"). Finally, concerns about purity referred to the rejection of contagion, contamination, pollution and the profane through feelings of disgust and dislike, and it is based on an idea of the sacredness of body and soul (e.g., "not having dirty thoughts").

Based on the set of moral concerns raised in previous studies, the authors of the Moral Foundations Questionnaire formulated a first version that only evaluated the relevance of major moral concerns for testing ideological differences between liberals and conservatives. They were able to organize a way to measure and describe how people, groups and cultures differ in their moral concerns (Graham, Haidt \& Nosek, 2009). Subsequently, following the development of the questionnaire, a section with sentences as specific and contextual moral judgments was included to measure the level of agreement with each of them. According to the authors, such variation in item format and content measures not only sensitivity in relation to moral concerns but also opinions on moral issues (Graham et al., 2011).

Analyzes of the final version of the questionnaire were performed on a sample of 34,476 adults, who filled in the relevance and moral judgment sections through the online questionnaire. In the original study (Graham et al., 2011), exploratory factor analyzes indicated the existence of two factors regarding relevance items and judgment items. Factor loadings ranged from 0.40 to 0.70 in Factor 1 (entitled binding, gathering in-group, authority, and purity items), and 0.47 to 0.65 in Factor 2 (entitled individualizing, gathering harm and fairness items) of the relevance section. In the judgment section, factor loadings varied between 0.34 and 0.67 in Factor 1, and between 0.27 and 0.63 in Factor 2. Unfortunately, the authors of the original study did not include information on the percentage of variance explained by the model.

Results of confirmatory analyzes suggested a five-factor model (harm, fairness, authority, in-group, and purity) as more appropriate than other models with one, two (individualizing concerns corresponding to the items of harm and fairness, and binding concerns corresponding to the other items), three (corresponding to the three ethics autonomy, community and divinity of Shweder, 2003), or six factors (adding tradition to the other five factors described above). Due to the association between the factors observed in the exploratory factor analysis, the authors of the original study also tested a hierarchical model, with two second-order factors called individualizing (including items relating to harm and fairness), and binding (including items related to 
in-group, authority, and purity). At the end of exhaustive studies to adjust the number of items, as well as a series of correlations with other scales, the final versions consist of 30 items (full version) and 20 items (abbreviated version).

For the five-factor model, a test-retest reliability analysis was also performed, with indexes ranging from 0.69 (ingroup) to 0.82 (purity) after an average interval of 37 days. In terms of external validity, significant correlations of each moral foundation proposed with their respective values were observed on the Schwartz Values Scale. Additionally, the authors report that women had higher scores for harm, fairness and purity, while men had higher scores for in-group and authority (Graham et al, 2011).

The MFQ has since been translated into several languages and used to evaluate morality in different populations, contexts and objectives. Recent studies show that the MFQ can be used to meet a variety of goals, and it is directed to a wide range of interests in the field of moral psychology (Aharoni, Kiehl \& Antonenko, 2011; Boer \& Fischer, 2013; Cornwell \& Higgins, 2013; Dogruel, Joekel \& Bowman, 2013; Graham, Nosek \& Haidt, 2012; Noser et al., 2015).

Due to the relevance of the theme, this study aimed at seeking validity evidence for the MFQ, and providing an adequate psychological instrument to Brazilian researchers (Mansur-Alves, Silva \& Fernandes, 2016; Primi, 2010), focused on the social-intuitionist approach of the moral phenomenon. To this end, two studies were conducted focusing on (1) translation, adaptation and verification of psychometric parameters of the MFQ, and (2) confirmation of the MFQ factor structure translated and adapted to the Brazilian context. The two studies are presented below in sequence.

\section{STUDY I}

\section{Method}

Participants. Taking part in the study were 341 adults (see Table 1). They are Internet users, aged predominantly between $21-28$ years ( $37 \%$ ) and $28-35$ years ( $26 \%$ ), mostly women $(63 \%)$ from all Brazilian regions, with predominance of the southeast region (65.7\%). The sample composition followed two exclusion criteria: nationality (foreigner) and age (under 18 years old).

Instrument. For this study, respondents answered a questionnaire consisting of the following instruments:

Moral Foundations Questionnaire (MFQ). The Brazilian-Portuguese version of the MFQ (Graham et al., 2011) was translated by experts. The instrument consists of 30 items that are divided into two parts, with 15 items each. The first part of the instrument evaluates moral relevance (for example, "How relevant you consider whether or not someone was denied his or her rights") using a Likert scale ranging from 0 (not at all relevant) to 5 (extremely relevant). The second part of the instrument assesses moral judgments about moral concerns in a contextual way (e.g., "It is more important to be a team player than to express oneself") using a Likert scale ranging from 0 (strongly disagree) and 5 (strongly agree).

Sociodemographic questions. To characterize study participants, information was collected on age, gender and geographical location.

\section{Procedure.}

MFQ translation and adaptation. The process of translation (adaptation of the first step of the method of Beaton, Bombardier, Guillemin \& Ferraz, 2000) consisted of three steps, always followed by the submission of the material to the responsible researcher: (1) translation into Brazilian Portuguese by a bilingual researcher; (2) review by two bilingual researchers for verification of semantic equivalence between the original and the translated version; and (3) review of the version reviewed by two independent experts in moral psychology.

Participants were recruited from the general population using the snowball sampling technique, through a standardized message sent to the email addresses registered in the researcher's contact list and on social networks, available online for about 50 days. The instrument was presented in virtual format and filled in anonymously, voluntarily, without remuneration and upon acceptance of the informed consent form. Those who agreed went to the first page of the questionnaire, while those who disagreed were guided to a page thanking them for their interest in participating in the research. The MFQ was presented in a fixed form on three virtual pages, containing moral relevance, moral judgment, and sociodemographic questions, respectively. It was possible to review what had already been filled in via the back icon, but it was not possible to go forward without checking off all items on the page. At the end of the questionnaire, it was necessary 
Table 1

Sociodemographic characteristics of Men and Women of the Study 1 Sample

\begin{tabular}{|c|c|c|c|}
\hline Variable & $\begin{array}{c}\text { Total } \\
(\mathrm{n}=\mathbf{3 4 1})\end{array}$ & $\begin{array}{c}\text { Men } \\
(n=126)\end{array}$ & $\begin{array}{c}\text { Women } \\
(n=215)\end{array}$ \\
\hline \multicolumn{4}{|l|}{ Age group } \\
\hline 18 to 20 & $29(8.5 \%)$ & $13(10.3 \%)$ & $16(7.4 \%)$ \\
\hline 21 to 28 & $120(35.2 \%)$ & $43(34.1 \%)$ & $77(35.8 \%)$ \\
\hline 29 to 35 & $92(27.0 \%)$ & $34(27.0 \%)$ & $58(27.0 \%)$ \\
\hline 36 to 42 & $39(11.4 \%)$ & $16(12.7 \%)$ & $23(10.7 \%)$ \\
\hline 43 to 49 & $31(9.1 \%)$ & $7(5.6 \%)$ & $24(11.2 \%)$ \\
\hline 50 to 56 & $15(4.4 \%)$ & $6(4.8 \%)$ & $9(4.2 \%)$ \\
\hline 57 to 62 & $12(3.5 \%)$ & $6(4.8 \%)$ & $6(2.8 \%)$ \\
\hline 63 to 70 & $3(0.9 \%)$ & $1(0.8 \%)$ & $2(0.9 \%)$ \\
\hline \multicolumn{4}{|l|}{ Children } \\
\hline Yes & $87(25.5 \%)$ & $26(20.6 \%)$ & $61(28.4 \%)$ \\
\hline No & $254(74.5 \%)$ & $100(79,4)$ & $154(71.6 \%)$ \\
\hline \multicolumn{4}{|l|}{ Marital status } \\
\hline Single & $193(56.6 \%)$ & $77(61.1 \%)$ & $116(54.0 \%)$ \\
\hline Married & $134(39.3 \%)$ & $47(37.3 \%)$ & $87(40.5 \%)$ \\
\hline Divorced & $13(3.8 \%)$ & $2(1.6 \%)$ & $11(5.1 \%)$ \\
\hline Widowed & $1(0.3 \%)$ & $0(0.0 \%)$ & $1(0.5 \%)$ \\
\hline \multicolumn{4}{|l|}{ Religious belief } \\
\hline Yes & $234(68.6 \%)$ & 77 (61.1\%) & $157(73 \%)$ \\
\hline No & $107(31.4 \%)$ & $49(38.9 \%)$ & $58(27.0 \%)$ \\
\hline \multicolumn{4}{|l|}{ Religion } \\
\hline Catholic & $74(31.6 \%)$ & $14(18.2 \%)$ & $60(38.5 \%)$ \\
\hline Evangelical & $61(26.1 \%)$ & $23(29.9 \%)$ & $38(24.2 \%)$ \\
\hline Spiritist & $65(27.8 \%)$ & $25(32.5 \%)$ & $40(25.5 \%)$ \\
\hline Other & $15(6.4 \%)$ & $5(6.5 \%)$ & $10(6.5 \%)$ \\
\hline Not defined/not declared & $15(6.4 \%)$ & $8(10.4 \%)$ & $7(4.5 \%)$ \\
\hline No religion & $4(1.7 \%)$ & $2(2.6 \%)$ & $2(1.3 \%)$ \\
\hline \multicolumn{4}{|l|}{ Education level } \\
\hline Primary School (completed) & $2(0.6 \%)$ & $2(1.6 \%)$ & $0(0.0 \%)$ \\
\hline High School (completed) & $76(22.3 \%)$ & $33(43.4 \%)$ & $43(20.0 \%)$ \\
\hline College (completed) & $147(43.1 \%)$ & $55(16.1 \%)$ & $92(42.8 \%)$ \\
\hline Graduation & $116(34.0 \%)$ & $36(28.6 \%)$ & $80(37.2 \%)$ \\
\hline \multicolumn{4}{|l|}{ Currently working } \\
\hline Yes & $201(58.9 \%)$ & $78(61.9 \%)$ & $123(57.2 \%)$ \\
\hline No & $140(41.1 \%)$ & $48(38.1 \%)$ & $92(42.8 \%)$ \\
\hline \multicolumn{4}{|l|}{ Region of the country } \\
\hline North & $3(0.9 \%)$ & $1(0.8 \%)$ & $2(0.9 \%)$ \\
\hline Northeast & $43(12.6 \%)$ & $19(15.1 \%)$ & $24(11.2 \%)$ \\
\hline Central-West & $30(8.8 \%)$ & $14(11.1 \%)$ & $16(7.4 \%)$ \\
\hline Southeast & $224(65.7 \%)$ & $79(62.7 \%)$ & $145(67.4 \%)$ \\
\hline South & $41(12.0 \%)$ & $13(10.3 \%)$ & $28(13.1 \%)$ \\
\hline
\end{tabular}


to click the submit icon to have the forms submitted and computed for the study. The research was duly approved by the Human Research Ethics Committee (Protocol No. 29690314.3.0000.5542) prior to being performed.

Data analysis. Descriptive statistics and exploratory factor analyzes were performed using SPSS software (version 19). To evaluate the results of exploratory factor analysis (EFA), the criteria proposed by Damásio (2012) were used. The normal distribution of the items in the sample was tested in order to choose the most appropriate EFA to be performed, as well as Cronbach's alpha analysis.

\section{Results and Discussion}

In order to use the MFQ in the Brazilian context, and to present its validity evidence, the 30 items of the instrument were submitted to a sequence of analyzes. Based on the empirical median $(M d n=3.20)$, we used item discriminating analyses using high and low scoring groups. After defining the lower and upper criterion groups, Student's t-test was used with the total score of the scale. Results indicated that all translated items can significantly differentiate participants belonging to each group.

Then, the scale items were submitted to a KolmogorovSmirnov (K-S) test to verify their distribution. No item presented a normal distribution, suggesting the use of a Principal Axis Factoring (PAF) (Damásio, 2012). Sampling adequacy tests indicated that the data were adequate for factor analysis: Kaiser-Meyer-Olkin (KMO) Test $=0.87$; Bartlett's test of sphericity $=3983.14, \mathrm{p}<0.001$.

A PAF with varimax rotation was, then, conducted using the suggested theoretical criterion that recommends the existence of five factors, proposed by the authors of the instrument.. Results indicated that the five-factor solution was not adequate, and eigenvalues ranged from 0.64 to 7.06. The factor solution presented two factors with only two items, besides several items with factor loadings greater than $|0.30|$ in more than one factor.

Based on the scree plot observed in this first analysis and the factor solution presented, an additional analysis was performed, requesting two factors. This analysis presented more adequate indexes, altogether explaining $32.9 \%$ of the variance. According to Damásio (2012), there are no fixed and reliable values of variance explained percentage that can be considered an indication of the quality of the instrument tested. A review by this author reports that, in general, "factor solutions in psychology research explained less than $50 \%$ of overall variance" (Damásio, 2012, p. 222). In addition, the value of the variance explained was inversely associated with the number of items and sample size. Due to these results, there are no appropriate levels of variance explained that can be considered as an acceptable indicator of the quality of the instrument. In general, forcing more factors to encompass greater variance explained tends to create meaningless constructs.

The first factor, called binding morality, gathered items of authority $(04,10,15,20,26,31)$, in-group $(03,25,30)$, and purity $(05,16,21,27,32)$. This factor can be interpreted as attributing greater importance to socially normative aspects and to the morality of the social group to which the participant belongs, enabling the bond between the members of a given group, society or culture (Graham et al., 2011).

The second factor, called individualizing morality, gathered items of harm $(01,07,12)$, in-group $(09,14)$, and fairness $(02,08,13,18,24)$, and one item of purity (11). This factor can be interpreted as attributing importance to aspects related to justice and protection of the rights of the individual and/or group, differentiating the individual from others (Graham et al., 2011).

The PAF suggested the exclusion of items 17 ("Compassion for those who are suffering is the most crucial virtue"), 19 ("I am proud of my country's history"), 23 ("One of the worst things a person could do is hurt a defenseless animal"), 28 ("It can never be right to kill a human being"), and 29 ("I think it's morally wrong that rich children inherit a lot of money while poor children inherit nothing "), for presenting factor loading below the 0.30 criterion, thus being excluded.

The results described in this study, although similar to the hierarchical model predicted by the original study, differ from the five-factor structure proposed by Graham et al (2011), since only two dimensions were maintained in the process of adaptation and data analysis. Therefore, in order to verify the validity of this new structure, a second study was carried out using confirmatory factor analysis, as described below. 
Table 2

Factor Solution of the Moral Foundations Questionnaire (MFQ)

\begin{tabular}{|c|c|c|}
\hline \multirow{2}{*}{ Items } & \multicolumn{2}{|c|}{ Factor loading } \\
\hline & Factor 1 & Factor 2 \\
\hline 16. Whether or not someone acted in a way that God would approve of & 0.73. & 0.02 . \\
\hline 27. II would call some acts wrong on the grounds that they are unnatural & 0.71 . & 0.10 . \\
\hline 05 . Whether or not someone violated standards of purity and decency & 0.69. & 0.14 . \\
\hline 20. Respect for authority is something all children need to learn & 0.68 . & 0.05 . \\
\hline 10. Whether or not someone conformed to the traditions of society & 0.65 . & 0.07 . \\
\hline 32. Chastity is an important and valuable virtue & 0.64 . & 0.14 . \\
\hline 21. People should not do things that are disgusting, even if no one is harmed & 0.61 . & 0.07 . \\
\hline 04 . Whether or not someone showed a lack of respect for authority & 0.59 . & 0.14 . \\
\hline 03. Whether or not someone's action showed love for his or her country & 0.55 . & 0.06 \\
\hline 26. Men and women each have different roles to play in society & 0.55 . & 0.16 . \\
\hline $\begin{array}{l}\text { 31. If I were a soldier and disagreed with my commanding officer's orders, I would obey } \\
\text { anyway because that is my duty }\end{array}$ & 0.53 . & 0.16 \\
\hline 15. Whether or not an action caused chaos or disorder & 0.51 . & 0.24 \\
\hline $\begin{array}{l}\text { 25. People should be loyal to their family members, even when they have done something } \\
\text { wrong }\end{array}$ & 0.46 . & 0.14 . \\
\hline 30. It is more important to be a team player than to express oneself & 0.37 . & 0.08 \\
\hline 19. I am proud of my country's history & 0.29 . & 0.01 . \\
\hline 28. It can never be right to kill a human being & 0.28 . & 0.06 \\
\hline 08 . Whether or not someone acted unfairly & 0.06 . & 0.73 . \\
\hline 13. Whether or not someone was denied his or her rights & 0.18 & 0.71. \\
\hline 12. Whether or not someone was cruel & 0.05 . & 0.69 . \\
\hline 14. Whether or not someone showed a lack of loyalty & 0.20 . & 0.61 . \\
\hline 09. Whether or not someone did something to betray his or her group & 0.15 . & 0.61 . \\
\hline 07. Whether or not someone cared for someone weak or vulnerable & 0.12 . & 0.57 . \\
\hline 02. Whether or not some people were treated differently than others & 0.11 . & 0.55 . \\
\hline 11. Whether or not someone did something disgusting & 0.21 & 0.50 . \\
\hline 01 . Whether or not someone suffered emotionally & 0.06 . & 0.42 . \\
\hline 24. Justice is the most important requirement for a society & 0.13 . & 0.42 . \\
\hline $\begin{array}{l}\text { 18. When the government makes laws, the number one principle should be ensuring that } \\
\text { everyone is treated fairly }\end{array}$ & 0.02 . & 0.41 . \\
\hline 17. Compassion for those who are suffering is the most crucial virtue & 0.14 . & 0.28 . \\
\hline 23. One of the worst things a person could do is hurt a defenseless animal & 0.02 . & 0.28 . \\
\hline $\begin{array}{l}\text { 29. I think it's morally wrong that rich children inherit a lot of money while poor children } \\
\text { inherit nothing }\end{array}$ & 0.03 . & 0.13 . \\
\hline Eigenvalue & 6.96. & 2.90 . \\
\hline Variance explained & $23,21 \%$ & $9,68 \%$ \\
\hline Cronbach's Alpha & 0.84 & 0.89 . \\
\hline
\end{tabular}




\section{STUDY 2}

\section{Method}

Participants. Respondents were 371 adults (see Table 3 ). They were Internet users, predominantly between 21 and 35 years of age $(62.8 \%)$, mostly women $(61.2 \%)$ from all Brazilian regions, with predominance of the southeast region (70.9\%). The same exclusion criteria from Study 1 was applied.

Instrument. The same instruments of Study 1 were used, that is, the Moral Foundations Questionnaire (MFQ), and Sociodemographic Questions.

Procedure. The same procedure adopted in Study 1 was used.

Data analysis. Descriptive statistics and correlations were performed using SPSS software (version 19). Confirmatory factor analysis was performed using AMOS software, which considered the covariance matrix with the maximum likelihood estimator (MLE). The following indicators of model fit to data were used: chi-square to degrees of freedom ratio $(\chi 2 / \mathrm{df})$, which should present results below 3; goodness-of-fit index (GFI) and comparative fit index (CFI), which should have results equal to or above 0.90; and root mean square error of approximation (RMSEA), which should be equal to or below 0.08 (Byrne, 2001).

\section{Results}

In order to confirm the measure factor structure, the second sample $(\mathrm{N}=371)$ was used. Three models were tested: Model 1 - theoretically proposed model with five dimensions; Model 2 - two-factor model observed in the exploratory analysis; and Model 3 - alternative one-factor model. Results are presented in Table 4.

According to the results observed, Model 1 and Model 3 have indexes considered inadequate to the expected pattern. The two-factor Model 2 proposed in the exploratory analysis presented the most acceptable indexes. These results provide indicators of measure validity and reliability, indicating it is adequate to be used in the Brazilian context.

Table 3

Sociodemographic characteristics of Men and Women of the Study 2 Sample

\begin{tabular}{|c|c|c|c|}
\hline Variable & $\begin{array}{c}\text { Total } \\
(\mathrm{n}=\mathbf{3 7 1})\end{array}$ & $\begin{array}{c}\text { Men } \\
(n=144)\end{array}$ & $\begin{array}{c}\text { Women } \\
(\mathrm{n}=\mathbf{2 2 7})\end{array}$ \\
\hline \multicolumn{4}{|l|}{ Age group } \\
\hline 18 to 20 & $11(3.0 \%)$ & $5(3.5 \%)$ & $6(2.6 \%)$ \\
\hline 21 to 28 & $135(36.4 \%)$ & $50(37.4 \%)$ & $85(37.4 \%)$ \\
\hline 29 to 35 & $98(26.4 \%)$ & $49(34.0 \%)$ & $49(21.6 \%)$ \\
\hline 36 to 42 & $44(11.9 \%)$ & $15(10.4 \%)$ & $29(12.8 \%)$ \\
\hline 43 to 49 & $42(11.9 \%)$ & $13(9.0 \%)$ & $29(12.8 \%)$ \\
\hline 50 to 56 & $29(7.8 \%)$ & $9(6.3 \%)$ & $20(8.8 \%)$ \\
\hline 57 to 62 & $8(2.2 \%)$ & $3(2.1 \%)$ & $5(2.2 \%)$ \\
\hline 63 to 70 & $4(1.1 \%)$ & $0(0.0 \%)$ & $4(1.8 \%)$ \\
\hline \multicolumn{4}{|l|}{ Children } \\
\hline Yes & $72(19.4 \%)$ & $26(18.1 \%)$ & $46(20.3 \%)$ \\
\hline No & $299(80.6 \%)$ & $118(81.9 \%)$ & $181(79.7 \%)$ \\
\hline \multicolumn{4}{|c|}{ Marital status } \\
\hline Single & $180(48.5 \%)$ & $71(49.3 \%)$ & $109(48.0 \%)$ \\
\hline Married & $163(43.9 \%)$ & $66(45.8 \%)$ & 97 (42.7\%) \\
\hline Divorced & $26(7.0 \%)$ & $7(4.9 \%)$ & $19(8.4 \%)$ \\
\hline Widowed & $2(0.5 \%)$ & $0(0.0 \%)$ & $2(0.9 \%)$ \\
\hline \multicolumn{4}{|c|}{ Religious belief } \\
\hline Yes & $289(77.9 \%)$ & $106(73.6 \%)$ & $181(80.6 \%)$ \\
\hline No & $82(22.1 \%)$ & $38(26.4 \%)$ & $44(19.4 \%)$ \\
\hline
\end{tabular}




\begin{tabular}{|c|c|c|c|}
\hline Variable & $\begin{array}{c}\text { Total } \\
(\mathrm{n}=\mathbf{3 7 1})\end{array}$ & $\begin{array}{c}\text { Men } \\
(n=144)\end{array}$ & $\begin{array}{c}\text { Women } \\
(\mathrm{n}=\mathbf{2 2 7})\end{array}$ \\
\hline \multicolumn{4}{|l|}{ Religion } \\
\hline Catholic & $134(36.1 \%)$ & $55(38.2 \%)$ & $79(34.8 \%)$ \\
\hline Evangelical & $50(13.5 \%)$ & $17(11.8 \%)$ & $33(14.5 \%)$ \\
\hline Spiritist & $70(18.9 \%)$ & $25(17.4 \%)$ & $45(19.8 \%)$ \\
\hline Other & $8(2.2 \%)$ & $3(2.1 \%)$ & $5(2.2 \%)$ \\
\hline Not defined/not declared & $11(3.0 \%)$ & $4(2.8 \%)$ & $7(4.5 \%)$ \\
\hline No religion & $16(4.3 \%)$ & $2(1.4 \%)$ & $14(6.2 \%)$ \\
\hline \multicolumn{4}{|l|}{ Education level } \\
\hline Primary School (completed) & $1(0.3 \%)$ & $0(0.0 \%)$ & $1(0.4 \%)$ \\
\hline High School (completed) & $70(18.9 \%)$ & $34(23.6 \%)$ & $36(15.4 \%)$ \\
\hline College (completed) & $145(39.1 \%)$ & $73(50.7 \%)$ & $72(31.7 \%)$ \\
\hline Graduation & $155(41.8 \%)$ & $37(25.7 \%)$ & $118(52.0 \%)$ \\
\hline \multicolumn{4}{|l|}{ Currently working } \\
\hline Yes & $263(70.9 \%)$ & $115(79.9 \%)$ & $148(65.2 \%)$ \\
\hline No & $108(29.1 \%)$ & $29(20.1 \%)$ & $79(34.8 \%)$ \\
\hline \multicolumn{4}{|l|}{ Region of the country } \\
\hline North & $5(1.3 \%)$ & $1(0.7 \%)$ & $4(1.8 \%)$ \\
\hline Northeast & $31(8.4 \%)$ & $16(11.1 \%)$ & $15(6.6 \%)$ \\
\hline Central-West & $26(7.0 \%)$ & $16(11.1 \%)$ & $10(4.4 \%)$ \\
\hline Southeast & $263(70.9 \%)$ & $91(63.2 \%)$ & $172(75.8 \%)$ \\
\hline South & $46(12.4 \%)$ & $20(13.9 \%)$ & $26(11.4 \%)$ \\
\hline
\end{tabular}

Table 4

Confirmatory Factor Analysis of the Moral Foundations Questionnaire

\begin{tabular}{lccccccc}
\hline Models & $\chi^{2}$ & GI & $\chi^{2} /$ gl & GFI & AGFI & CFI & $\begin{array}{c}\text { RMSEA } \\
\text { (CI 95\% Min-Max) }\end{array}$ \\
\hline Model 1 & $1555.71^{* *}$ & 395. & 3.94. & 0.75. & 0.70. & 0.68. & $0.089(0.084-0.094)$ \\
Model 2 & $762.94^{* *}$ & 265. & 2.88. & 0.85. & 0.82. & 0.85. & $0.071(0.065-0.077)$ \\
Model 3 & $1069.33^{* *}$ & 265. & 4.03. & 0.77. & 0.72. & 0.75. & $0.091(0.085-0.096)$ \\
\hline
\end{tabular}

Note. $* p<0.05 ; * p<0.0$. Model 1 - five original theoretical factors; Model 2 - EFA two-factor solution observed; Model 3 - alternative one-factor solution.

\section{DISCUSSION}

This paper aimed at seeking validity evidence of the Moral Foundations Questionnaire for its use in the Brazilian context. Instead of using the reverse translation method, the chosen method of translation by specialists is considered more appropriate because it allows the assimilation of the idiomatic-cultural differences between American English and Brazilian Portuguese (Sandoval \& Duran, 1998).

The structure proposed by the authors of the original questionnaire contained 30 items divided into five dimensions, and two parts that assessed moral relevance and moral judgment. However, such a structure cannot be observed in the exploratory factor analyzes performed in Study 1, which suggested the need of a new study to confirm the results found.

Study 2 confirmed the structure found in Study 1, indicating a model composed of 25 items divided into two parts and two factors, or dimensions, for the Brazilian context. Although the Brazilian adaptation presented only two factors, compared to the five factors proposed by the American development study, it should be noted that the 
two-factor model is predicted in the original study as a hierarchical model, as second-order dimensions (Graham et al., 2011).

Individualizing moral concerns gathered items related to harm, fairness, and in-group, in addition to one purity item. The items apparently relate to the ethics of autonomy (Shweder et al, 1997), corresponding to the individualizing factor of the hierarchical model contained in the original American study. This factor was interpreted as attributing greater importance to aspects related to justice and protection of the rights of the individual and/or group, functioning as a particular moral characteristic of the individual in relation to others (Graham et al., 2011).

Two items that assessed relevance regarding in-group domain grouped with individualizing moral concerns ("Whether or not someone showed a lack of loyalty"; "Whether or not someone did something to betray his or her group"), as well as one item related to purity ("Whether or not someone did something disgusting"), instead of grouping with binding moral concerns. According to these results, in the context of the Brazilian sample, lack of loyalty, betrayal of one's own group and repugnance to an act seem to be interpreted more in an individual harm perspective than in relation to the effects they generate on the group. One possible explanation is that such acts, despite their consequences for the collective, are meant by the sample participants based on their personal experience of such situations, in a logic in which the individual and the collective would not be in opposite poles. In fact, according to Escóssia and Kastrup (2005), the individualsociety opposition should also be considered according to a non-dichotomous logic, for which the collective would be defined as a co-engendering plan between the individual and the social. As this is an unexpected bias in understanding moral relevance in the Brazilian context, it deserves to be explored in further studies.

Regarding items that evaluate harm, it is necessary to point out some other particularities. In this study, the three items that assess moral judgments regarding harm ("Compassion for those who are suffering is the most crucial virtue"; "One of the worst things a person could do is hurt a defenseless animal," and "It can never be right to kill a human being ") did not group with any of the factors. They were expected to make up the individualizing moral concerns, but the responses did not follow any pattern. A similar result occurred with the item that evaluated moral judgments on wealth as part of the notion of fairness ("I think it's morally wrong that rich children inherit a lot of money while poor children inherit nothing.") This item was expected to associate with the items of individualizing concerns factor; however, it did not group with any of the two factors. These findings may suggest that, for the Brazilian sample, causing the death of a human being (which excludes exceptions such as self-defense if considered as an act that can never be right, for example), feel compassion for human beings' suffering (without an explicit causative agent), causing harm to defenseless animals (without specifying whether the animal is domestic or part of the food chain), and concentrating wealth (inheritance for some children in detriment of others) appear to have shown no uniformity in moral judgment of the sample studied. It is possible that this result is reflecting, on the one hand, the generalist formulation (lack of specificity) of the item, and on the other, the fact that the sample did not show moral sensitivity in relation to such themes. Moreover, it is possible that moral judgment about the items has caused conscious rational thinking rather than intuition (Haidt, 2001), or that there is no socially modulated intuition about the themes in the context of Brazilian culture.

Regarding the binding moral concerns, the expected predominance of the items that evaluate the authority, ingroup and purity theoretical dimensions was verified. This factor was interpreted as attributing greater importance to socially normative aspects and to the morality of the social group to which the participant belongs, and its characteristic is to promote bond between the members of a given group, society or culture (Graham et al., 2011). This finding corroborates the theoretical proposal of an ethics of community and divinity (Shweder et al, 1997), for which each person is somehow linked to others, helping to maintain the social organization, as well as the moral system that structure it (Haidt \& Kessebir, 2010).

The item that evaluates the moral judgment regarding the historical context and nationality, inserted in the in-group context ("I am proud of my country's history") was the only one of this factor that did not group with any of the two factors. The exclusion of this and the other items cited possibly suggests specificity related to the socio-cultural context that underlies the Brazilians' moral judgment. It is worth noting that according to the functionalist perspective of moral systems, psychological mechanisms, along with the set of values, virtues, norms, practices, identities, institutions and technologies, regulate social life, making it possible (Haidt \& Kessebir, 2010). In this sense, it is possible to speculate that, given the profusion of recent and controversial events in the country's history related to the issue of morality, the item may have caused in the participants a rational rather than an intuitive evaluation. However, it is important to note that all the 15 items assessing moral relevance presented validity evidence.

Although this study did not find the structure proposed by the authors of the original scale, the results of confirmatory factor analyzes indicate that the two-factor structure does not differ significantly from the five-factor structure. A 
recent study, which proposed an adaptation of the MFQ comparing it with a measure of religiosity (Silvino et al., 2016), also found a two-factor structure for the version presented, which corroborates the results found in this study. Thus, the two-factor model is considered more appropriate for the Brazilian sample studied, since it does not exclude theoretical content and presents internal consistency and other acceptable psychometric parameters, in addition to adequate fit indicators that meet the values suggested by the literature (Byrne, 2001).

The fact that the studies were performed virtually may have been one of their limitations. It is recommended that new samples should use the traditional in-person paper-andpencil procedure to test whether the factor structure observed is confirmed. Another fact to be considered about the study sample characterization is the predominance of participants from the southeastern region, which may have resulted in a moral judgment assessment with a specific perspective related to an urban population, with good socioeconomic conditions and Internet access.

In general, however, it is possible to state that the psychometric characteristics of the scale are compatible with the original American study. The high internal consistency values are quite satisfactory and indicate the reliability of the MFQ. Confirmatory factor analysis indicates that the MFQ assesses a two-dimension construct, as predicted in the hierarchical model of the American study. The results obtained support the validity and reliability of the questionnaire, so that this instrument can contribute to studying the moral psychology field. In order to deepen the work initiated here, further research is recommended, especially regarding its multidimensional structure.

\section{REFERENCES}

Aharoni, E., Antonenko, O., \& Kiehl, K. A. (2011). Disparities in the moral intuitions of criminal offenders: The role of psychopathy. Journal of Research in Personality, 45(3), 322-327.

Beaton, D. E., Bombardier, C., Guillemin, F., \& Ferraz, M. B. (2000). Guidelines for the process of cross-cultural adaptation of self-report measures. Spine, 25(24), 3186-3191.

Boer, D., \& Fischer, R. (2013). How and when do personal values guide our attitudes and sociality? Explaining cross-cultural variability in attitude-value linkages. Psychological Bulletin, 139(5), 1113-1147.

Byrne, B. M. (2001). Structural equation modeling with AMOS: Basic concepts, applications, and programming. Mahwah, NJ: Erlbaum.

Cornwell, J. F., \& Higgins, E. T. (2013). Morality and its relation to political ideology: The Role of promotion and prevention concerns. Personality and Social Psychology Bulletin, 39(9), 1164-1172.

Cushman, F., Young, L., \& Hauser, M. (2006). The role of conscious reasoning and intuition in moral judgment: Testing three principles of harm. Psychological Science, 17, 1082-1089.

Damásio, B. F. (2012). Uso da análise fatorial exploratória em psicologia. Avaliação Psicológica, 11(2), 213-228.

Dogruel, L., Joeckel, S., \& Bowman, N. D. (2013). Elderly people and morality in virtual worlds: A cross-cultural analysis of elderly people's morality in interactive media. New Media \& Society, 15(2), 276-293.

Douglas, M. (1966). Purity and danger. London, England: Routledge. doi: 10.4324./9780203361832

Escóssia, L., \& Kastrup, V. (2005). O conceito de coletivo como superação da dicotomia indivíduo-sociedade. Psicologia em Estudo, 10(2), 295-304

Fiske, A. P. (1992). The four elementary forms of sociality: Framework for a unified theory of social relations. Psychological Review, 99, 689-723.

Graham, J., Haidt, J., \& Nosek, B. A. (2009). Liberals and conservatives rely on different sets of moral foundations. Journal of Personality and Social Psychology, 96(5), 10291046.

Graham, J., Meindl, P., Beall, E., Johnson, K. M., \& Zhang, L. (2016). Cultural differences in moral judgment and behavior, across and within societies. Current Opinion in Psychology, $8,125-130$.
Graham, J., Nosek, B. A., Haidt, J., Iyer, R., Koleva, S., \& Ditto, P. H. (2011). Mapping the moral domain. Journal of Personality and Social Psychology, 101, 366-385.

Graham, J., Nosek, B. A., \& Haidt, J. (2012). The moral stereotypes of liberals and conservatives: Exaggeration of differences across the political spectrum. PloS one, 7(12), e50092.

Haidt, J. (2001). The emotional dog and its rational tail: a social intuitionist approach to moral judgment. Psychological Review, $108,814-834$.

Haidt, J. (2007). The new synthesis in moral psychology. Science, 316, 998-1001.

Haidt, J., \& Graham, J. (2007). When morality opposes justice: Conservatives have moral intuitions that liberals may not recognize. Social Justice Research, 20(1), 98-116.

Haidt, J., \& Joseph, C. (2007). The moral mind: How five sets of innate intuitions guide the development of many culturespecific virtues, and perhaps even modules. In P. Carruthers, S. Laurence, \& S. Stich (Orgs.), The Innate Mind, 3 (pp. 367-392). Oxford: Oxford University Press.

Haidt, J., \& Kesebir, S. (2010). Morality. In S. T. Fiske, D. T. Gilbert, \& G. Lindzey (Orgs.), Handbook of Social Psychology (pp.797832). New Jersey: Wiley.

Haidt, J., Koller, S. H., \& Dias, M. (1993). Affect, culture, and morality, or is it wrong to eat your dog?. Journal of Personality and Social Psychology, 65, 613-28.

Hofmann, W., Wisneski, D. C., Brandt, M. J., \& Skitka, L. J. (2014). Morality in everyday life. Science, 345(6202), 1340-1343.

Jansson, J., \& Dorrepaal, E. (2015). Personal norms for dealing with climate change: results from a survey using moral foundations theory. Sustainable Development, 23, 381-395. doi: 10.1002/ sd. 1598 .

Mansur-Alves, M., Silva, R. S., \& Fernandes, S. C. D. Á. (2016). Impact of the Psychological Testing Assessment System (SATEPSI) for scientific publications in psychological assessment. Psico-USF, 21, 179-188.

Moll, J., Oliveira-Souza, D., \& Zahn, R. (2008). The neural basis of moral cognition. Annals of the New York Academy of Sciences, 1124(1), 161-180.

Noser, A. E., Zeigler-Hill, V., Vrabel, J. K., Besser, A., Ewing, T. D., \& Southard, A. C. (2015). Dark and immoral: The links between pathological personality features and moral values. Personality and Individual Differences, 75, 30-35. 
Primi, R. (2010). Avaliação psicológica no Brasil: Fundamentos, situação atual e direções para o futuro. Psicologia: Teoria e Pesquisa, 26(spe), 25-35. https://dx.doi.org/10.1590/S010237722010000500003

Rest, J., Narvaez, D., Bebeau, M., \& Thoma, S. (1999). A neo-Kohlbergian approach: The DIT and schema theory. Educational Psychology Review, 11(4), 291-324.

Rozin, P., Haidt, J., \& McCauley, C.R. (2000). Disgust. In M. Lewis \& J. Haviland (Ed.), Handbook of emotions ( $2^{\mathrm{a}}$ ed., pp. $637-$ 653). New York, NY: Guilford Press.

Sandoval, J., \& Durán, R. P. (1998). Language. In J. Sandoval, C. L. Frisby, K. F. Geisinger, J. D. Scheuneman, \& J. R. Grenier (Orgs.), Test Interpretation and diversity: Achieving equity in assessment wording (pp. 181-211). Washington, DC: American Psychological Association.

Silvino, A. M. D., Pilati, R., Keller, V. N., Silva, E. P., Freitas, A. F. D. P., Silva, J. N., \& Lima, M. F. (2016). Adaptation of the
Moral Foundations Questionnaire to Brazilian Portuguese. Psico-USF, 21(3), 487-495.

Shweder, R.A., Much, N., Park, L., \& Mahapatra, M. M. (1997). The 'Big Three' of Morality (Autonomy, Community, Divinity) and the 'Big Three' Explanations of Suffering. In A. M. Brandt \& P. Rozin (Eds.), Morality and health (pp. 119-169). Florence, KY, US: Taylor \& Frances/Routledge.

Weber, C. R., \& Federico, C. M. (2013). Moral foundations and heterogeneity in ideological preferences. Political Psychology, 34(1), 107-126.

Wheatley, T., \& Haidt, J. (2005). Hypnotic disgust makes moral judgments more severe. Psychological Science, 16, 780-784.

Yilmaz, O., Harma, M., Bahçekapili, H. G., \& Cesur, S. (2016). Validation of the Moral Foundations Questionnaire in Turkey and its relation to cultural schemas of individualism and collectivism. Personality and Individual Differences, 99, 149-154. 